Supporting Information

\title{
1,4-Dioxane-Specific Organic Hosts and Their Polymorphism
}

Vikrant Jayant, Dinabandhu Das ${ }^{*}$

School of Physical Sciences, Jawaharlal Nehru University, New Delhi-110067, India

\section{Synthesis}

Synthetic scheme for compound $\mathbf{1}$ and $\mathbf{2}$ is shown in Scheme S1. These compounds were synthesized by a literature reported procedure. ${ }^{1}$

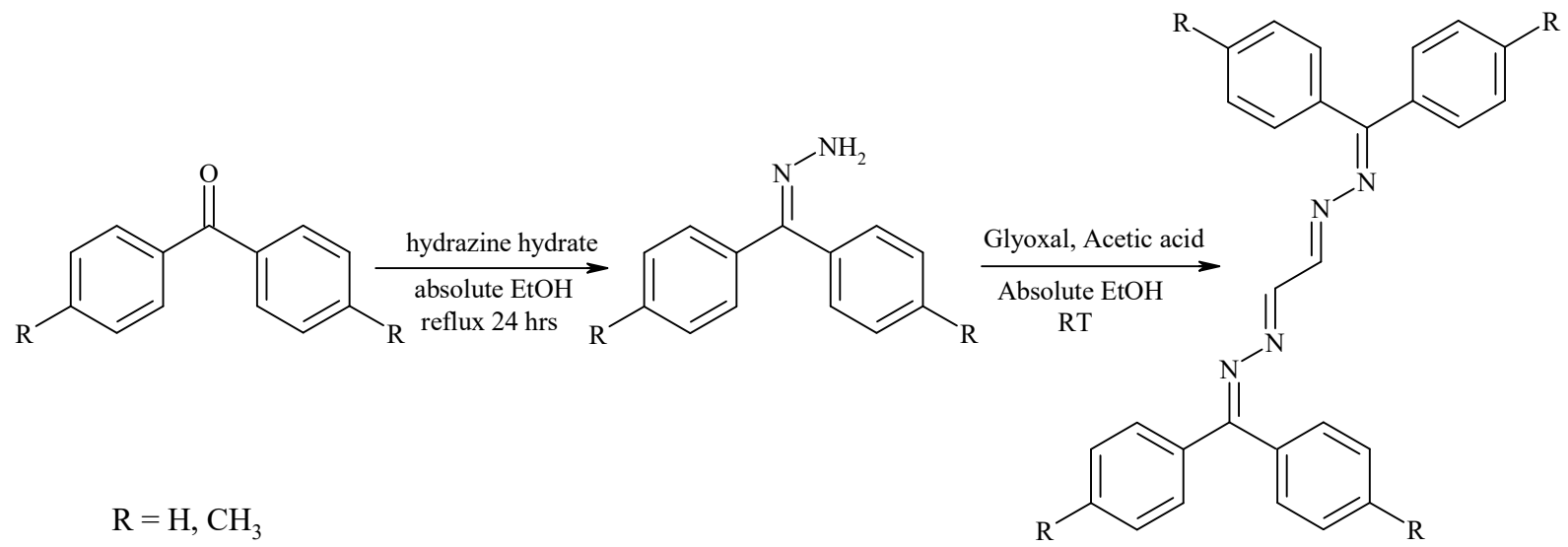

\section{Scheme S1}

NMR and MS data for compound 1:

${ }^{1} \mathrm{H}$ NMR (500 MHz, $\left.\mathrm{CDCl}_{3}\right): \delta 7.245-7.676(\mathrm{~m}, 20 \mathrm{H}), \delta 8.148(\mathrm{~s}, 2 \mathrm{H})$

TOF-MS (m/z): 415.0973(100\%), 234.0213(48\%)

NMR and MS data for compound 2:

${ }^{1} \mathrm{H}$ NMR (500 MHz, $\mathrm{CDCl}_{3}$ ): $\delta 7.595$ (d, 4H), $\delta 7.167$ - 7.247 (m, 12H), $\delta 2.56(\mathrm{~d}, 12 \mathrm{H})$

TOF-MS (m/z): 471.1586 (100\%), 262.0493 (17\%) 


\section{Crystallization:}

Both the compounds were crystallized by slow evaporation method in varieties of solvents and mixture of solvents. Solvents used for crystallization and the outcome of the crystallization are shown in Table S1 and S2 for compound 1 and $\mathbf{2}$ respectively.

Table S1 Solvents used for crystallization of compound 1 and composition of crystals produced

\begin{tabular}{|c|c|}
\hline Solvent used for crystallization of 1 & Crystalline form obtained \\
\hline DCM & 1a \\
\hline $\mathrm{CHCl}_{3}$ & 1a \\
\hline $\mathrm{THF}+\mathrm{CHCl}_{3}$ & $1 \mathrm{a}$ \\
\hline Ethyl Acetate & $1 \mathbf{a}$ \\
\hline 1,4-Dioxane & 1•DIOX \\
\hline Benzene + Acetone & 1a \\
\hline Fluorobenzene + DCM & $\mathbf{1 a}$ \\
\hline Hexafluorobenzene + DCM & 1a \\
\hline Nitromethane $+\mathrm{CHCl}_{3}$ & $\mathbf{1 a}$ \\
\hline Toluene $+\mathrm{CHCl}_{3}$ & 1a \\
\hline Mesitylene $+\mathrm{CHCl}_{3}$ & $1 \mathbf{a}$ \\
\hline m-Nitrotoluene $+\mathrm{CHCl}_{3}$ & $1 \mathbf{a}$ \\
\hline Acetone & $1 \mathrm{a}$ \\
\hline Pyridine $+\mathrm{CHCl}_{3}$ & 1a \\
\hline Acetonitrile $+\mathrm{CHCl}_{3}$ & $\mathbf{1 a}$ \\
\hline o-Xylene $+\mathrm{CHCl}_{3}$ & $1 \mathrm{a}$ \\
\hline $\mathrm{m}$-Xylene $+\mathrm{CHCl}_{3}$ & 1a \\
\hline $\mathrm{p}$-Xylene $+\mathrm{CHCl}_{3}$ & $1 \mathrm{a}$ \\
\hline $\mathrm{MeOH}+\mathrm{CHCl}_{3}$ & 1a \\
\hline $\mathrm{EtOH}+\mathrm{CHCl}_{3}$ & 1a \\
\hline $\mathrm{i}-\mathrm{PrOH}+\mathrm{CHCl}_{3}$ & $1 \mathbf{a}$ \\
\hline t-Butanol $+\mathrm{CHCl}_{3}$ & $1 \mathrm{a}$ \\
\hline Cyclohexane + DCM & $1 \mathrm{a}$ \\
\hline Cyclohexanone $+\mathrm{CHCl}_{3}$ & 1a \\
\hline Diethylether $+\mathrm{CHCl}_{3}$ & $1 \mathbf{a}$ \\
\hline $\mathrm{DMA}+\mathrm{CHCl}_{3}$ & $1 \mathrm{a}$ \\
\hline $\mathrm{DMF}+\mathrm{CHCl}_{3}$ & $\mathbf{1 a}$ \\
\hline $\mathrm{DMSO}+\mathrm{CHCl}_{3}$ & $1 \mathrm{a}$ \\
\hline $\mathrm{THF}+\mathrm{CHCl}_{3}$ & $1 \mathrm{a}$ \\
\hline Nitrobenzene $+\mathrm{CHCl}_{3}$ & 1a \\
\hline
\end{tabular}




\begin{tabular}{|l|l|}
\hline Anisole $+\mathrm{CHCl}_{3}$ & 1a \\
\hline Hexane $+\mathrm{DCM}$ & $\mathbf{1 a}$ \\
\hline Water + DCM & $\mathbf{1 a}$ \\
\hline o-Xylene+Toluene & $\mathbf{1 b}$ \\
\hline
\end{tabular}

Table S2. Solvents used for crystallization of compound $\mathbf{2}$ and composition of crystals produced

\begin{tabular}{|c|c|}
\hline Solvent used for crystallization of 2 & Crystalline form obtained \\
\hline DCM & $2 \mathbf{a}$ \\
\hline $\mathrm{CHCl}_{3}$ & $\mathbf{2 a}$ and $\mathbf{2 b}$ concomitantly \\
\hline $\mathrm{THF}+\mathrm{CHCl}_{3}$ & $2 a$ \\
\hline Ethyl Acetate & $2 \mathbf{a}$ \\
\hline 1,4-Dioxane & $2 \cdot \mathrm{DIOX}$ \\
\hline Benzene + Acetone & $\mathbf{2 a}$ and $\mathbf{2 b}$ concomitantly \\
\hline Fluorobenzene + DCM & $\mathbf{2 a}$ and $\mathbf{2 b}$ concomitantly \\
\hline Hexafluorobenzene + DCM & $\mathbf{2 a}$ and $\mathbf{2 b}$ concomitantly \\
\hline Nitromethane $+\mathrm{CHCl}_{3}$ & $\mathbf{2 a}$ and $\mathbf{2 b}$ concomitantly \\
\hline Toluene $+\mathrm{CHCl}_{3}$ & $2 \mathbf{2 b}$ \\
\hline Mesitylene $+\mathrm{CHCl}_{3}$ & $\mathbf{2 a}$ and $\mathbf{2 b}$ concomitantly \\
\hline m-Nitrotoluene $+\mathrm{CHCl}_{3}$ & $\mathbf{2 a}$ and $\mathbf{2 b}$ concomitantly \\
\hline Acetone & $2 \mathbf{2 a}$ \\
\hline Pyridine $+\mathrm{CHCl}_{3}$ & $\mathbf{2 a}$ and $\mathbf{2 b}$ concomitantly \\
\hline Acetonitrile $+\mathrm{CHCl}_{3}$ & $\mathbf{2 a}$ and $\mathbf{2 b}$ concomitantly \\
\hline o-Xylene $+\mathrm{CHCl}_{3}$ & $\mathbf{2 a}$ and $\mathbf{2 b}$ concomitantly \\
\hline $\mathrm{m}$-Xylene $+\mathrm{CHCl}_{3}$ & $\mathbf{2 a}$ and $\mathbf{2 b}$ concomitantly \\
\hline p-Xylene $+\mathrm{CHCl}_{3}$ & $\mathbf{2 a}$ and $\mathbf{2 b}$ concomitantly \\
\hline $\mathrm{MeOH}+\mathrm{CHCl}_{3}$ & $2 \mathbf{a}$ \\
\hline $\mathrm{EtOH}+\mathrm{CHCl}_{3}$ & 2a \\
\hline $\mathrm{i}-\mathrm{PrOH}+\mathrm{CHCl}_{3}$ & $2 \mathbf{b}$ \\
\hline t-Butanol $+\mathrm{CHCl}_{3}$ & $2 \mathbf{a}$ \\
\hline Cyclohexane + DCM & $2 \mathbf{2 a}$ \\
\hline Cyclohexanone $+\mathrm{CHCl}_{3}$ & $2 \mathbf{2 a}$ \\
\hline Diethylether $+\mathrm{CHCl}_{3}$ & $2 \mathbf{a}$ \\
\hline $\mathrm{DMA}+\mathrm{CHCl}_{3}$ & $2 \mathbf{2 a}$ \\
\hline $\mathrm{DMF}+\mathrm{CHCl}_{3}$ & $2 a$ \\
\hline $\mathrm{DMSO}+\mathrm{CHCl}_{3}$ & $2 a$ \\
\hline Furan $+\mathrm{CHCl}_{3}$ & $2 \mathbf{2 a}$ \\
\hline
\end{tabular}




\begin{tabular}{|l|c|}
\hline Aniline + benzene & $\mathbf{2 a}$ \\
\hline Nitrobenzene $+\mathrm{CHCl}_{3}$ & $\mathbf{2 a}$ and $\mathbf{2 b}$ concomitantly \\
\hline Anisole $+\mathrm{CHCl}_{3}$ & $\mathbf{2 a}$ and $\mathbf{2 b}$ concomitantly \\
\hline Hexane $+\mathrm{DCM}$ & $\mathbf{2 a}$ \\
\hline Water + DCM & $\mathbf{2 a}$ \\
\hline Mesitylene & $\mathbf{2 b}$ \\
\hline
\end{tabular}

Thermal ellipsoid plots.

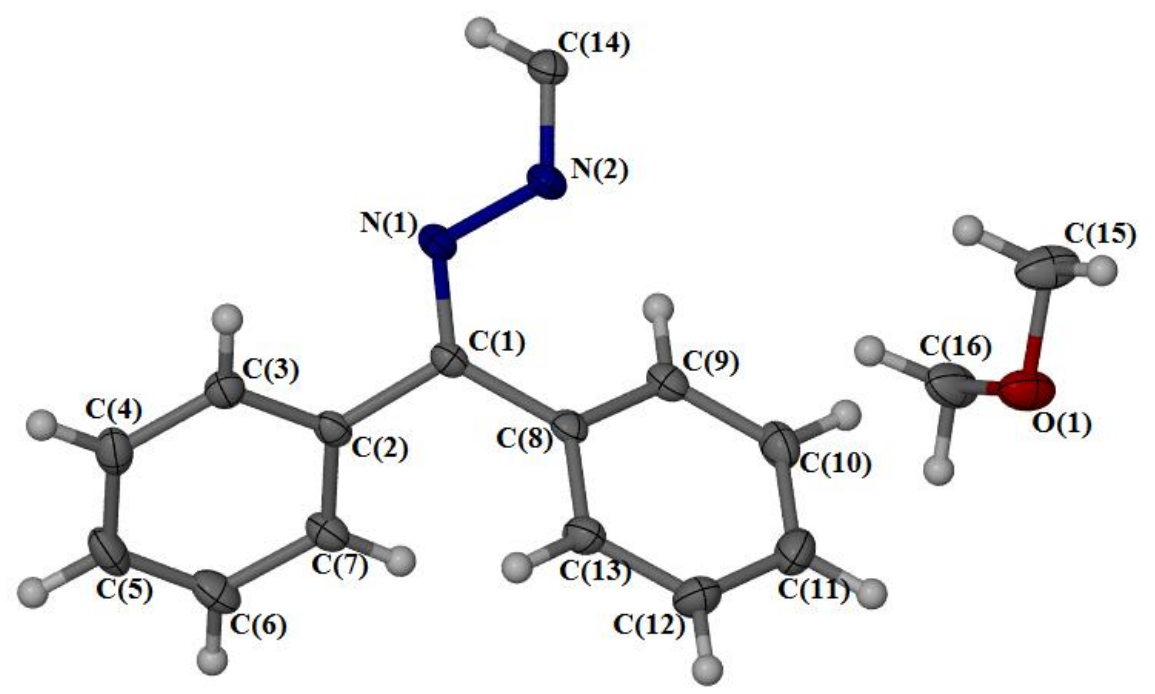

Figure S1. Thermal ellipsoid plot of asymmetric unit of 1•DIOX. Atoms are shown with $70 \%$ probability of thermal ellipsoids.

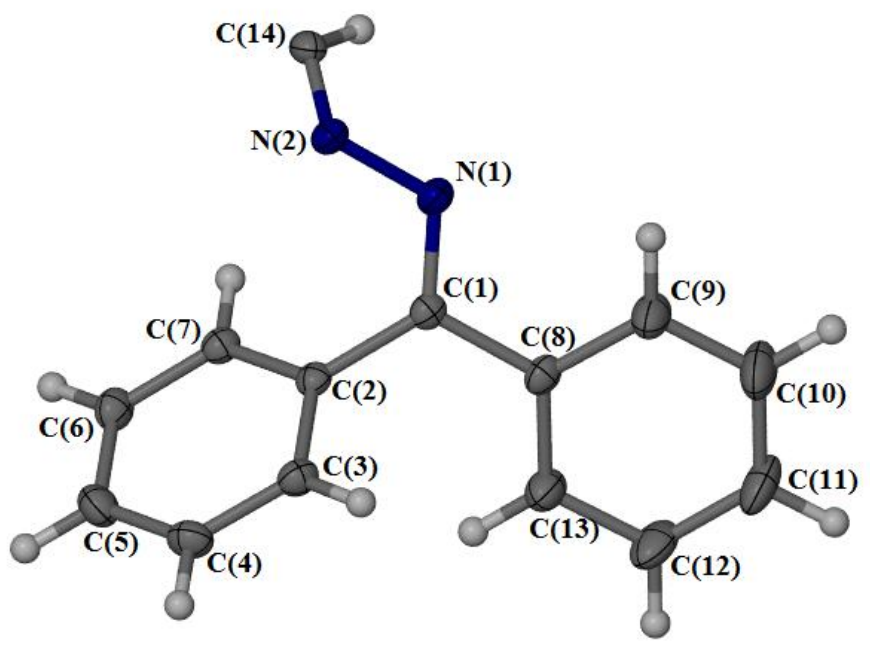


Figure S2. Thermal ellipsoid plot of asymmetric unit of 1a. Atoms are shown with $70 \%$ probability of thermal ellipsoids.

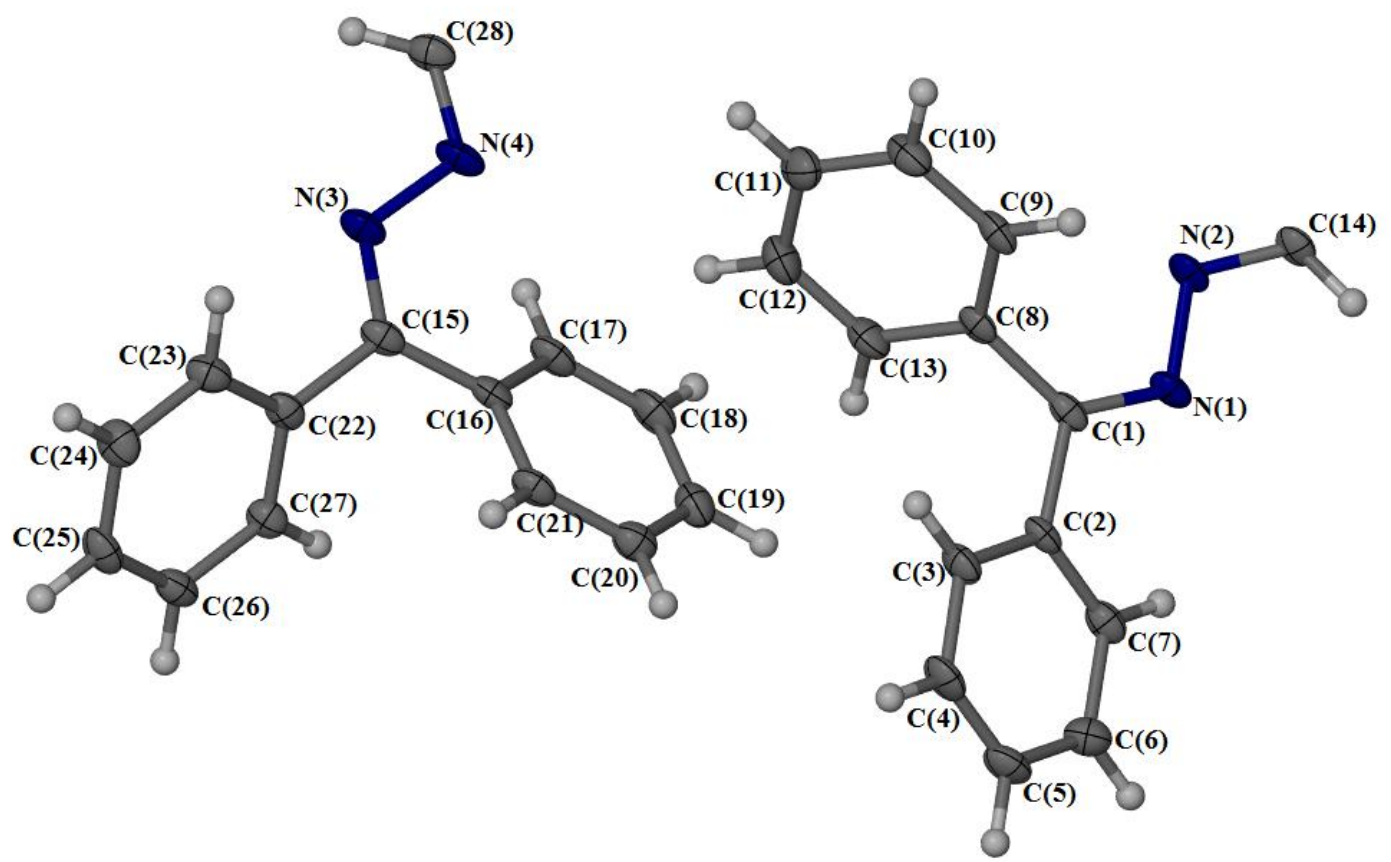

Figure S3. Thermal ellipsoid plot of asymmetric unit of $\mathbf{1 b}$. Atoms are shown with $70 \%$ probability of thermal ellipsoids.

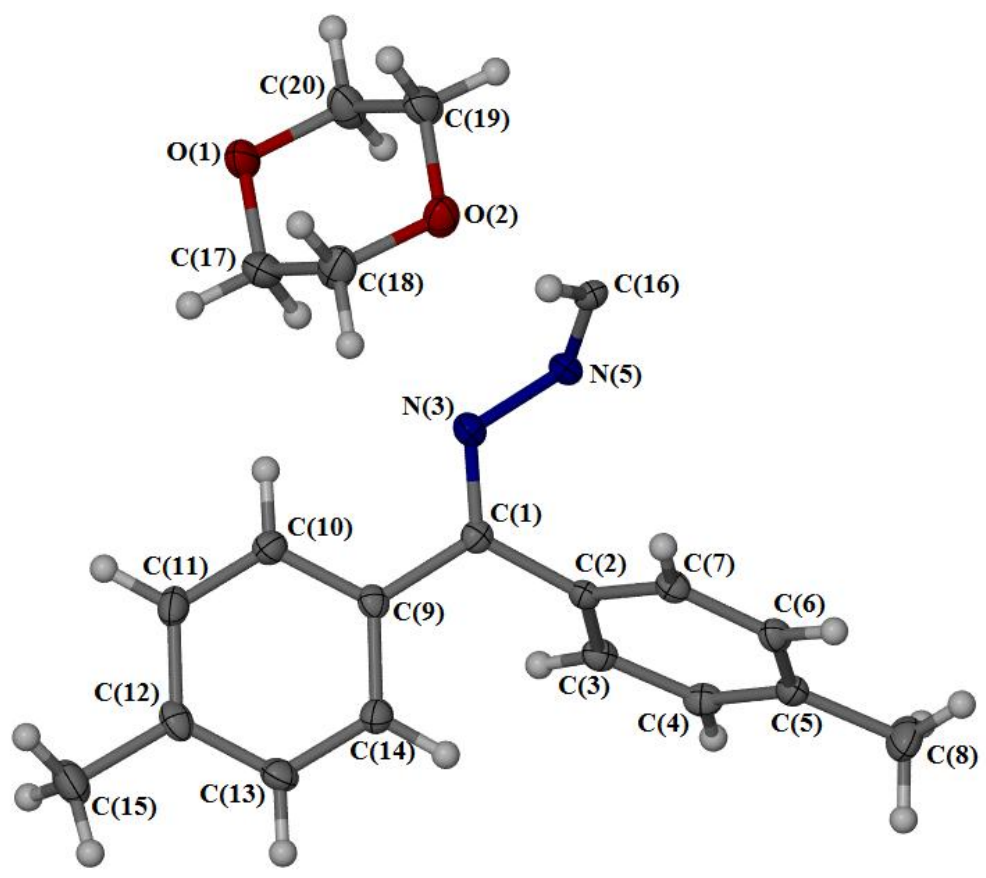


Figure S4. Thermal ellipsoid plot of asymmetric unit of 2-DIOX. Atoms are shown with $70 \%$ probability of thermal ellipsoids.

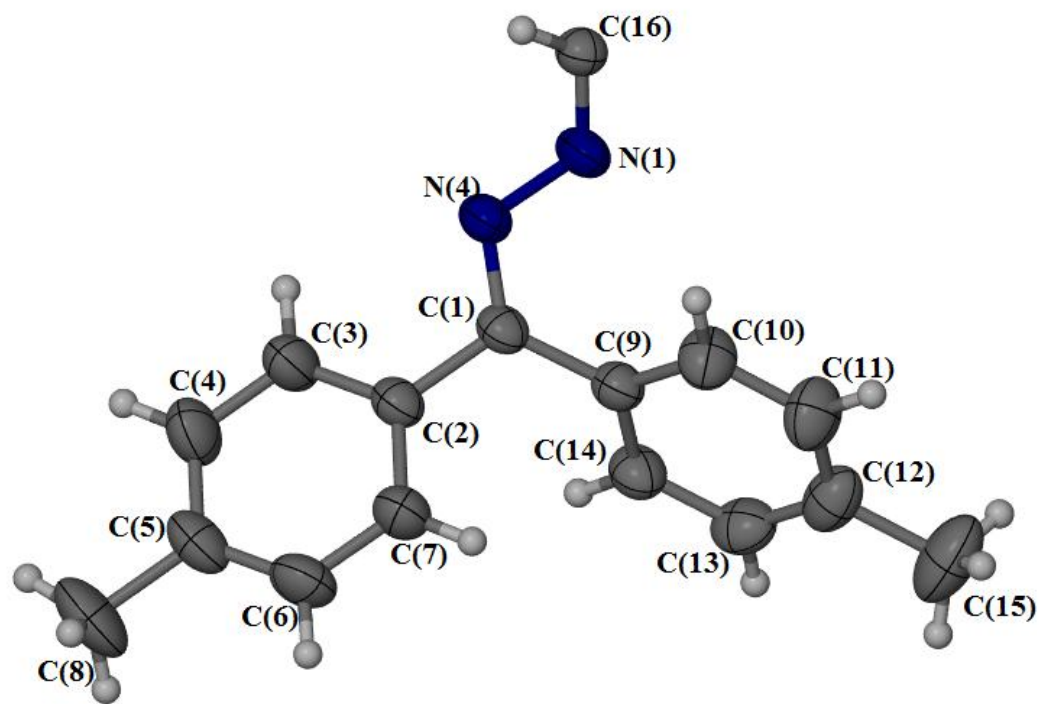

Figure S5. Thermal ellipsoid plot of asymmetric unit of 2a. Atoms are shown with 50\% probability of thermal ellipsoids.

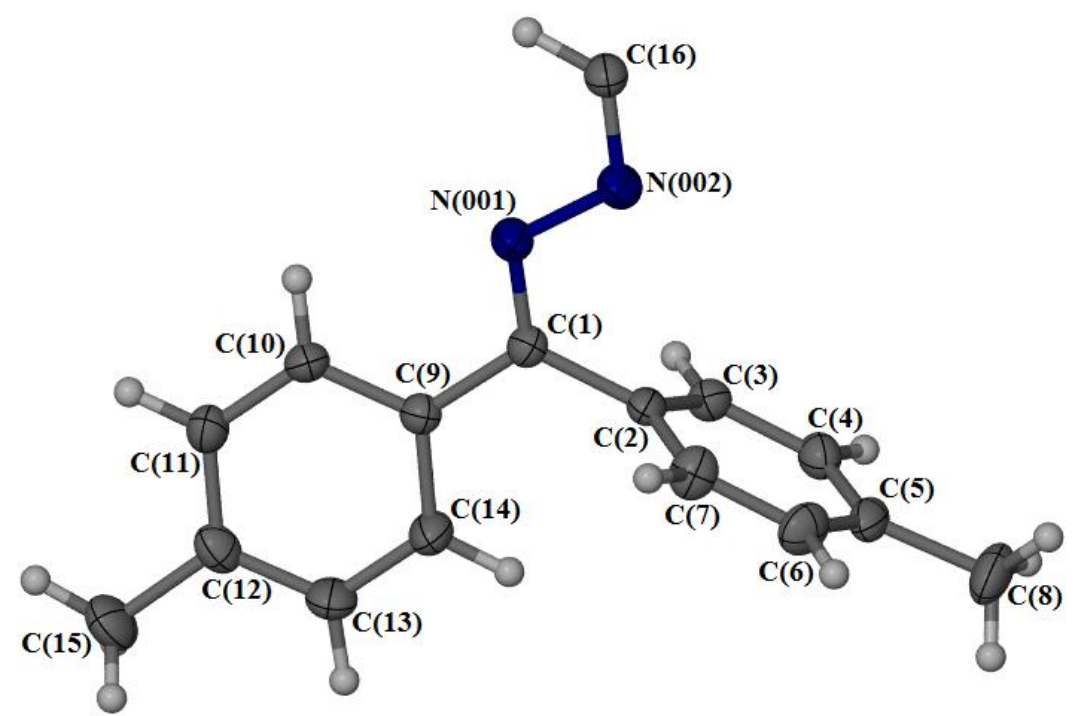

Figure S6. Thermal ellipsoid plot of asymmetric unit of $\mathbf{2 b}$. Atoms are shown with $70 \%$ probability of thermal ellipsoids. 


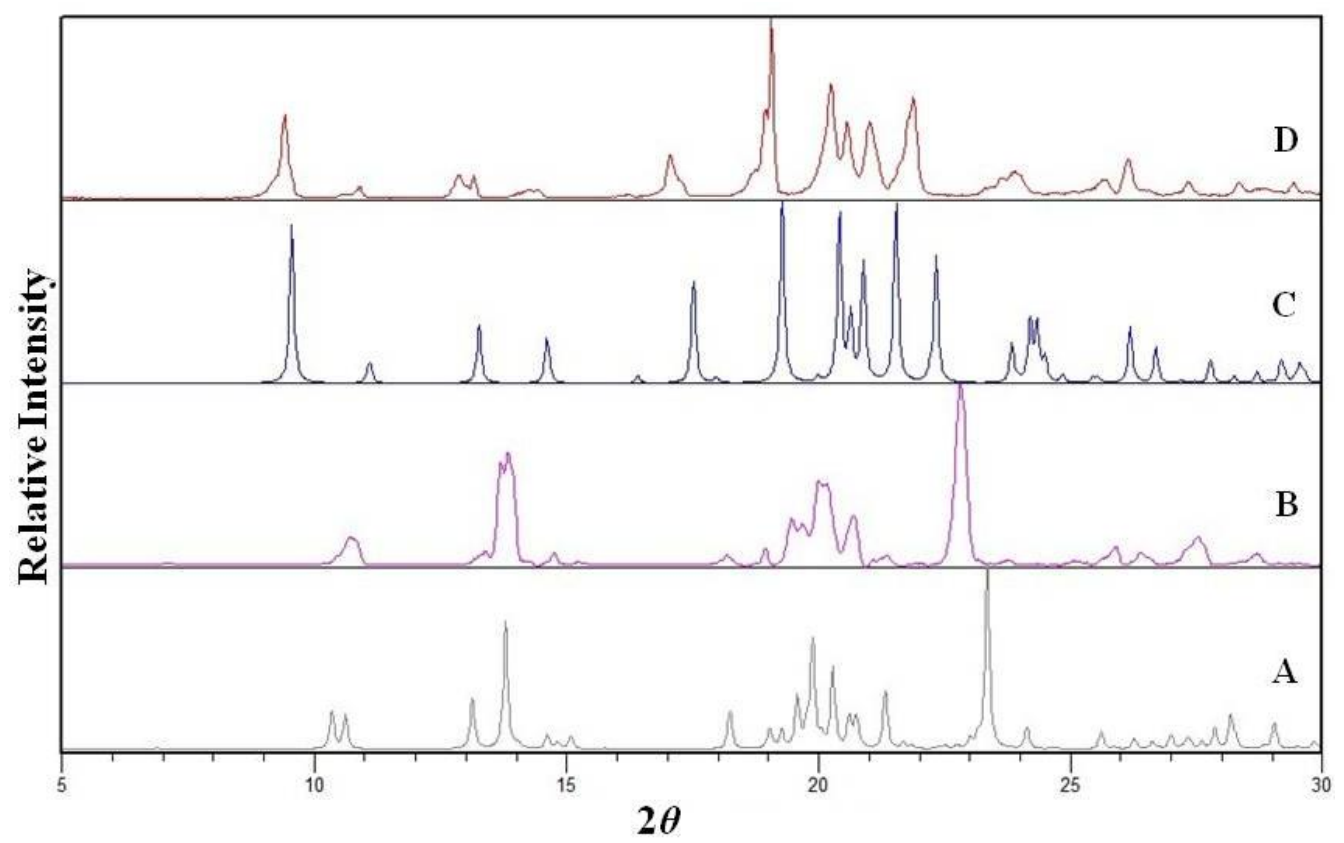

Figure S7. PXRD pattern of $\mathbf{1 b}$ calculated (A), $\mathbf{1 b}$ experimental before heating at $125^{\circ} \mathrm{C}(\mathrm{B})$, $1 \mathrm{a}$ calculated (C) and after heating the sample of $\mathbf{1 b}$ at $125^{\circ} \mathrm{C}$ for 48 hours (D)

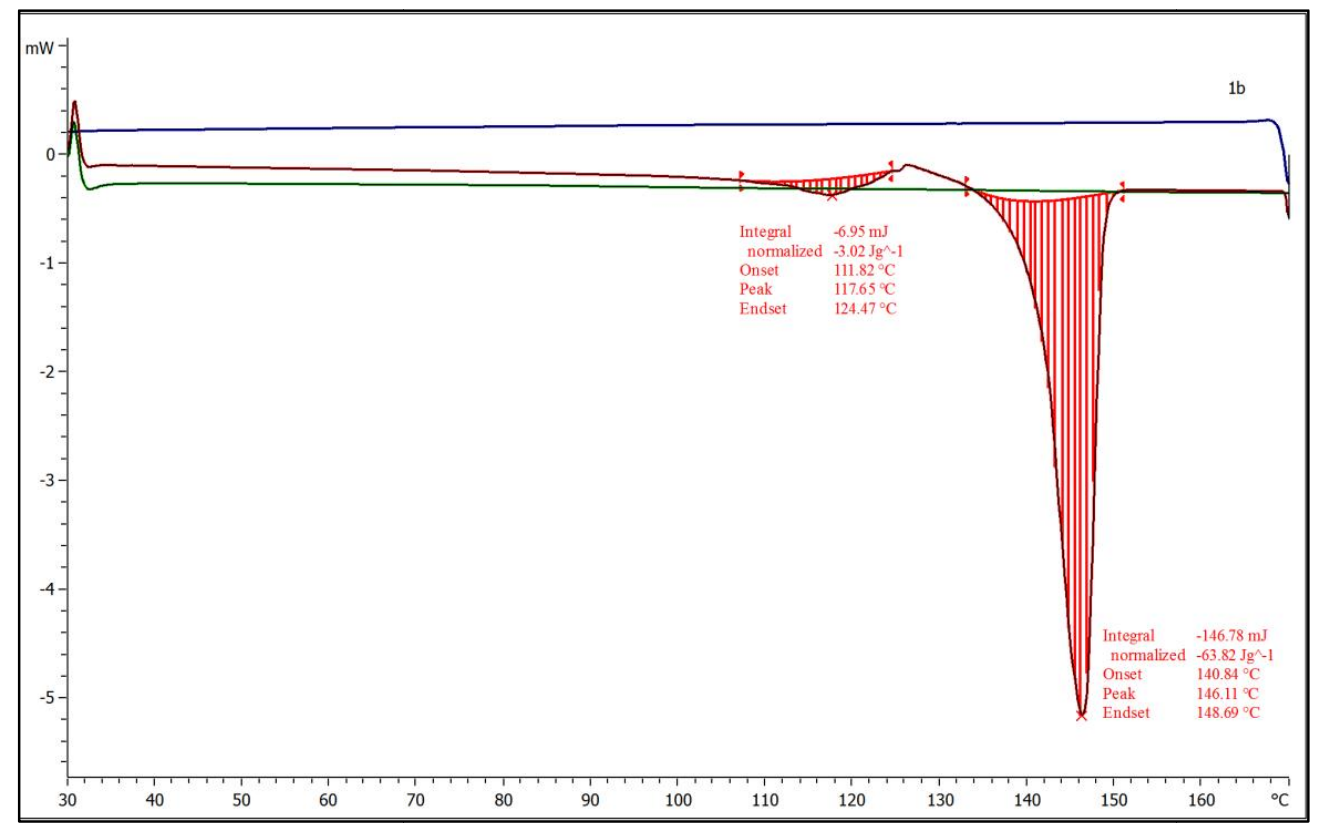

Figure S8. DSC thermogram of $\mathbf{1 b}$ by heat-cool-heat method @ $10^{\circ} \mathrm{C} / \mathrm{min}$. Red color plot shows the conversion of $1 \mathbf{b}$ to $1 \mathrm{a}$ at $124.5^{\circ} \mathrm{C}$ followed by melting at around $146{ }^{\circ} \mathrm{C}$. Blue color curve shows no crystallization during cooling from $170^{\circ} \mathrm{C}$ to room temperature. Green curve shows no thermal event during re-heating. 


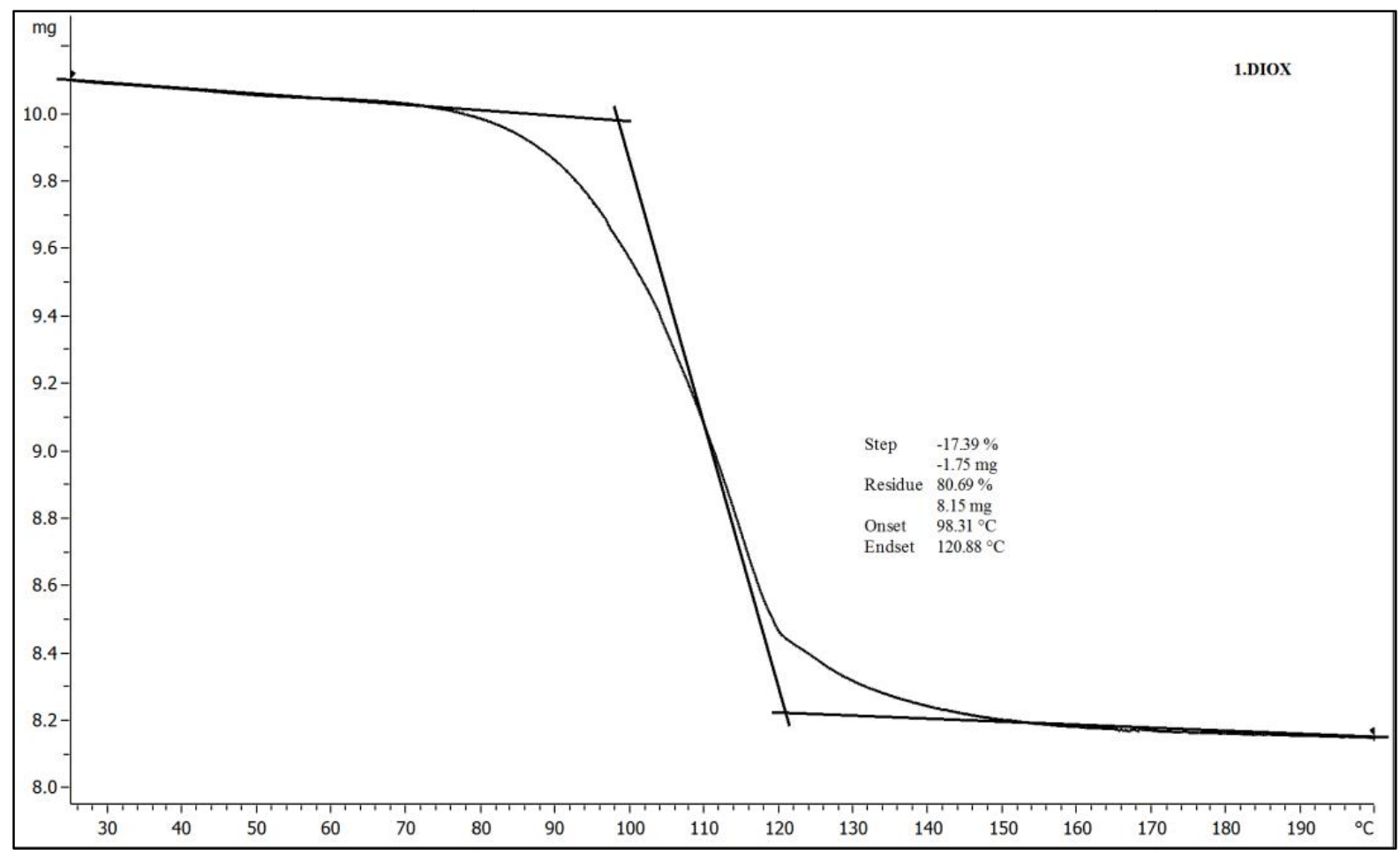

Figure S9. TGA thermogram of 1•DIOX showing mass loss of $18.5 \%$ from $98.8^{\circ} \mathrm{C}$ to $122.3^{\circ} \mathrm{C}$.

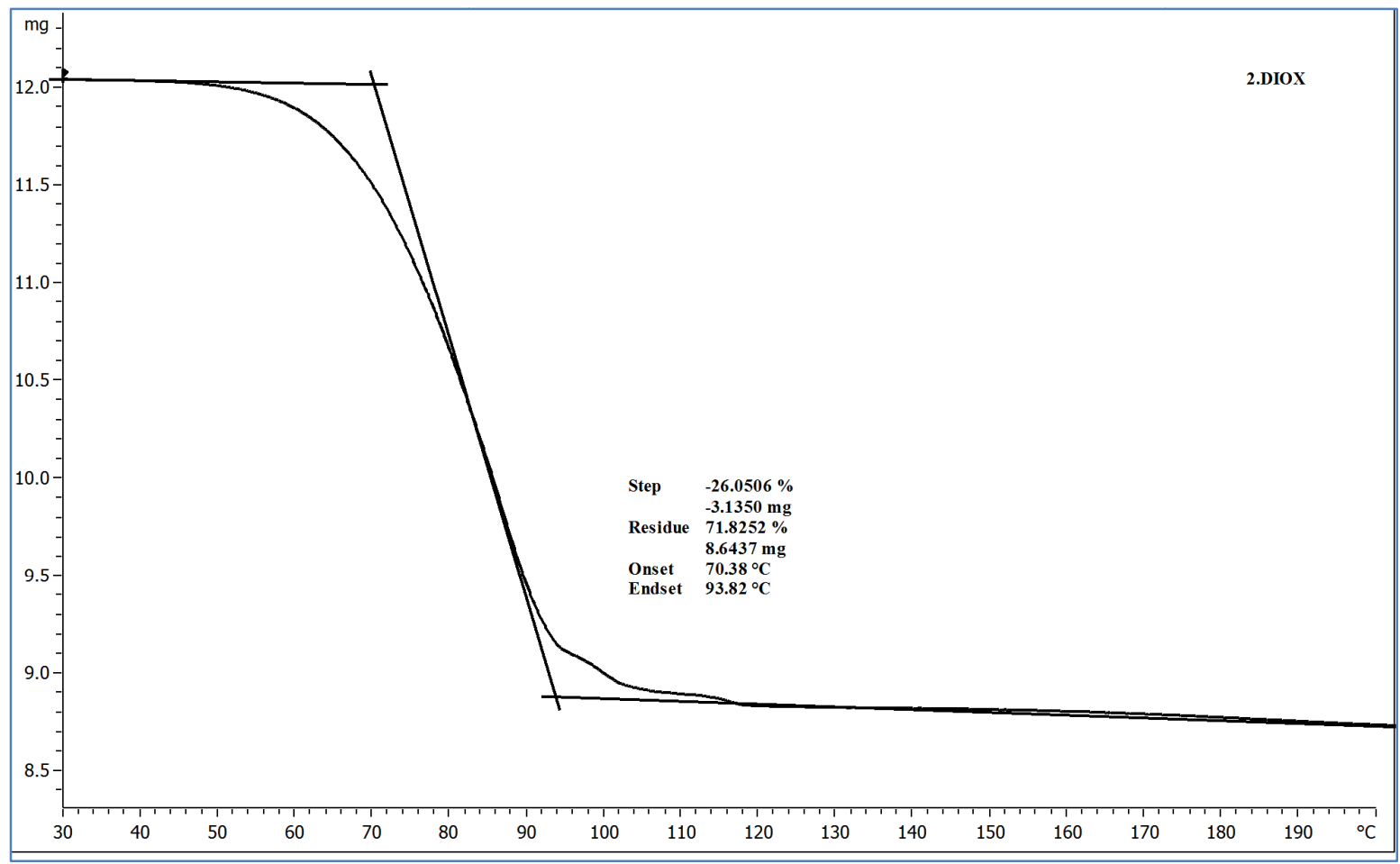

Figure S10. TGA thermogram of 2•DIOX showing mass loss of $26 \%$ from $70.4^{\circ} \mathrm{C}$ to $94.2^{\circ} \mathrm{C}$. 